\title{
Changes in circulating IGF1 receptor stimulating activity do not parallel changes in total IGF1 during GH treatment of GH-deficient adults
}

\author{
Aimee J Varewijck, Steven W J Lamberts, A J van der Lely, \\ Sebastian J C M M Neggers, Leo J Hofland and Joseph A M J L Janssen
}

Division of Endocrinology, Department of Internal Medicine, Room D-443, Erasmus MC, 's-Gravendijkwal 230, 3015 CE Rotterdam, The Netherlands
Correspondence should be addressed to J A M J L Janssen Email

j.a.m.j.l.janssen@ erasmusmc.nl

\begin{abstract}
Context: Previously we demonstrated that IGF1 receptor stimulating activity (IGF1RSA) offers advantages in diagnostic evaluation of adult GH deficiency (GHD). It is unknown whether IGF1RSA can be used to monitor GH therapy. Objective: To investigate the value of circulating IGF1RSA for monitoring GH therapy. Design/methods: 106 patients ( $54 \mathrm{~m} ; 52 \mathrm{f}$ ) diagnosed with GHD were included; 22 were GH-naïve, 84 were already on GH treatment and discontinued therapy 4 weeks before baseline values were established. IGF1RSA was determined by the IGF1R kinase receptor activating assay, total IGF1 by immunoassay (Immulite). GH doses were titrated to achieve total IGF1 levels within the normal range.

Results: After 12 months, total IGF1 and IGF1RSA increased significantly (total IGF1 from $8.1(95 \% \mathrm{Cl} 7.3-8.9)$ to $14.9(95 \% \mathrm{Cl}$ 13.5-16.4) nmol/l and IGF1RSA from 115 (95\% Cl 104-127) to 181 (95\% Cl 162-202) pmol//). After 12 months, total IGF1 normalized in $81 \%$ of patients, IGF1RSA in $51 \%$ and remained below normal in more than $40 \%$ of patients in whom total IGF1 had normalized.

Conclusions: During 12 months of GH treatment, changes in IGF1RSA did not parallel changes in total IGF1. Despite normalization of total IGF1, IGF1RSA remained subnormal in a considerable proportion of patients. At present our results have no short-term consequences for GH therapy of GHD patients. However, based on our findings we propose future studies to examine whether titrating GH dose against IGF1RSA results in a better clinical outcome than titrating against total IGF1.
\end{abstract}

\section{Introduction}

Growth hormone deficiency (GHD) in adults is characterized by perturbations in body composition, carbohydrate and lipid metabolism, bone mineral density, cardiovascular risk profile and quality of life $(1,2)$. At present, diagnosis is made on the basis of one (or two) abnormal provocative tests (GH-releasing hormone (GHRH)-arginine test or insulin tolerance test) (3). Although GH is considered to be the main regulator of circulating insulin-like growth factor 1 (IGF1), there is a significant overlap of IGF1 levels between healthy and GHD subjects. Up to half of all individuals with confirmed GHD have IGF1 levels within the low-normal age-dependent range $(4,5,6)$.

During GH therapy, GH dose is titrated against total IGF1 levels and the consensus guidelines advise that 'values should be kept within the age-related normal range' $(3,7)$. Thus, the values of total IGF1 can be normal to begin with and yet that is the goal of treatment. Previous studies have shown that the relationship between serum IGF1 response during GH treatment and other treatment effects such as metabolic endpoints and body composition is poor $(8,9)$. In addition, it has been 
reported that long-term monitoring of GH therapy by using age- and sex-adjusted normal serum total IGF1 values, might lead to different dose adjustments when different total IGF1 immunoassays are used (10).

As almost all IGF1 in blood is bound with high affinity to IGF-binding proteins (IGFBPs) techniques have been developed to remove or inactivate IGFBPs to overcome assay interference (11). However, many of the methods currently used for measuring circulating total IGF1 levels are hampered by interferences of IGFBPs that remain present after incomplete extraction (12). In addition, by extracting IGFBPs, the modifying effects of these proteins on IGF1 action are systematically ignored. In 2003, a kinase receptor activation (KIRA) bioassay was developed by Chen et al. (13) that was able to measure circulating IGF1 receptor stimulating activity (IGF1RSA) at physiological conditions. The principle of this assay is based on quantification of IGF1R activation after stimulation with serum in vitro (13). In this way, circulating IGF1RSA is quantified while taking into account the modifying effects of IGFBPs and IGFBP proteases on the interactions between IGF1 and the IGF1R. Previously, we demonstrated that circulating IGF1RSA offers advantages over total IGF1 in the diagnostic evaluation of adult GHD (6). As such it can be hypothesized that the measurement of circulating IGF1RSA can also be used to monitor GH therapy. The aim of the present study was to investigate the value of circulating IGF1RSA for monitoring GH therapy.

\section{Patients and methods}

\section{Study population}

Our study population has been previously described in a report on IGF1RSA in GHD patients during GH treatment when we concluded that the circulating IGF1RSA might reflect different aspects of quality of life than total IGF1 in these subjects (14). In short, 106 patients diagnosed with GHD by GH-provocative tests were included. Eighty-four patients were diagnosed as adult onset GHD (AO-GHD) and 22 as childhood onset GHD (CO-GHD). These 84 patients had already been treated with recombinant human GH, while 22 patients were GH-naïve. Four patients had isolated GHD, 11 patients had one additional pituitary hormone deficiency, 23 patients had two additional pituitary hormone deficiencies and 68 patients had had three or more additional pituitary hormone deficiencies.

For the diagnosis of GHD, patients with multiple pituitary hormone deficits had to have a serum GH peak below the cut-off value in one $\mathrm{GH}$ provocative test (arginine-GHRH test: GH peak $<16.5 \mu \mathrm{g} / \mathrm{l}$ and insulin tolerance test: $\mathrm{GH}$ peak $<5.0 \mu \mathrm{g} / \mathrm{l})$ and patients with isolated GHD needed two abnormal outcomes in different $\mathrm{GH}$ provocative tests. Inclusion criteria were: i) age between 18 and 80 years, ii) written voluntary informed consent and iii) subjects using hormone replacement therapy for additional pituitary deficits had to be on an optimized treatment regimen for at least 3 months prior to inclusion. Exclusion criteria were: i) patients who had received certain types of therapies for other reasons such as radiotherapies, surgeries, chemo-or immunotherapies in the 3 months prior to study start. ii) Female patients who were pregnant or lactating, or who wanted to become pregnant within 1 year. iii) Subjects who, in the judgment of the investigators, were likely to be non-compliant or uncooperative during the study. From all subjects informed consent was obtained and the study was approved by the Medical Ethics Committee of Erasmus MC.

\section{Study design}

After inclusion, all 84 patients who had already been treated with recombinant human GH were asked to discontinue GH treatment for 4 weeks. All patients were studied at baseline and 12 months. The 84 patients were using different brands of recombinant human GH. After 4 weeks, baseline values were established and patients restarted their $\mathrm{GH}$ treatment. No patient was switched from one recombinant $\mathrm{GH}$ product to another. The $22 \mathrm{GH}$ naïve patients were studied before starting GH therapy and 12 months thereafter. GH dose was adjusted targeting serum total IGF1 concentrations to the middle $(Z$-score $=0)$ of the normal age-related reference values for the healthy population (15). The following laboratory assessments were conducted in the fasting state: circulating IGF1RSA, total IGF1, insulin, glucose, IGFBP1 and IGFBP3. Moreover, body weight, height and blood pressure were measured. Fat mass percentage was assessed by bioelectrical impedance (using an Omron Body Composition Monitor with a hand-to-hand method, Omron, Hoofddorp, The Netherlands). BMI and waist-to-hip ratio (WHR) were calculated. The updated homeostasis model assessment (HOMA-2) was used to assess insulin resistance (HOMA-IR) and beta cell function (HOMA-B) from pairs of fasting glucose and insulin levels (16). Percentages of IGF1RSA over total IGF1 were calculated by dividing circulating IGF1RSA (nmol/l) by total IGF1 (nmol/l) and multiplying by 100 . Duration of GHD was defined as the 
time that had elapsed since GHD diagnosis (confirmed by a $\mathrm{GH}$ provocative test) up to the date of inclusion in this study.

\section{Blood measurements}

The IGF1R KIRA assay has been previously described $(13,17)$. Briefly, IGF1 binding to the IGF1R results in autophosphorylation of tyrosine residues located within the intracellular kinase domain, being the first step in the intracellular signaling cascade. The IGF1R KIRA assay uses a human embryonic kidney (HEK) cell line that is stably transfected with the human IGF1R gene (HEK IGF1R) and quantifies phosphorylation of tyrosine residues of the transfected IGF1R in vitro to assess circulating IGF1RSA. After $48 \mathrm{~h}$ of culture HEK IGF1R cells were stimulated for $15 \mathrm{~min}$ at $37^{\circ} \mathrm{C}$ with increasing known amounts of human recombinant IGF1 (Invitrogen) in a range of 0.06-1.0 nmol/1 and study serum samples. In addition, two control serum samples were tested on every plate to ensure optimal performance. Standards and serum samples were diluted in Krebs-Ringer bicarbonate buffer adjusted to $\mathrm{pH} 7.4$ by $\mathrm{CO}_{2}$ and supplemented with $0.1 \%$ human serum albumin (Octalbine; Octopharma, Lachen, Switzerland). After stimulation cells were lysed. Crude lysates were transferred to a sandwich assay. Wells were coated with a MAB directed against the IGF1R (MAD1; Novozymes-Gropep, Adelaide, SA, Australia) that was used as capture antibody in a concentration of $5.0 \mu \mathrm{g} / \mathrm{ml}$. An europium labelled monoclonal anti-phosphotyrosine antibody (Eu-PY20; Perkin-Elmer Life Sciences, Groningen, The Netherlands) was used as a detection antibody in a concentration of $1.25 \mu \mathrm{g} / \mathrm{ml}$. Contents were read in a time-resolved fluorometer (Victor2 multilabel counter; Perkin-Elmer Life Sciences). Assays were performed in 48 well plates (Corning Inc., Corning, NY, USA). For measurements of circulating IGF1RSA, an IGF1 standard, two internal control samples were included on each culture plate. Serum samples were diluted 1/10. All measurements were done in duplicate. The intra-assay and inter-assay coefficient of variations (CV) were below $15 \%$.

Serum total IGF1, IGFBP3 and insulin were measured by a solid-phase, enzyme-labeled chemiluminescent immunometric assays (intraassay $\mathrm{CV}$ were $3.9,4.4$ and $3.3-5.5 \%$, and interassay CV were 7.7, 6.6 and $4.1-7.3 \%$ respectively; Immulite 2000 supplied by Siemens Medical Solutions Diagnostics, Los Angeles, CA, USA).

Both circulating total IGF1 concentrations and IGF1RSA were compared with the age-specific normative range values for IGF1 that have been published before
$(17,18)$. For total IGF1 normal values have been established in serum samples collected from 1584 healthy individuals, neonates, infants, children, adolescents and adults up to the age of 88 years by an enzyme-labeled chemiluminescent immunometric assays (Immulite 2000). The normal ranges for IGF1RSA have been previously published by our group and have been determined by using the same IGF1R KIRA bioassay that was used in this study (17). These normal values were established by measuring IGF1RSA in serum samples from healthy, nonfasting blood donors (total $n=427$ ), whose ages ranged from 18 to 79 years (median: 44 years).

Both for circulating total IGF1 and IGF1RSA individual $Z$-scores were calculated using the following formula: $Z$-score $=(x$-average $x /$ S.D. $)$ where $x$ is the actual total IGF1 level or IGF1RSA, average $x$ is the mean total IGF1 level or IGF1RSA at that age, and S.D. for the mean at that age. We also calculated the IGF1/IGFBP3 ratio, since the molar ratio between IGF1 and IGFBP3 has been suggested to reflect an estimate of tissue available IGF1 (19).

Serum glucose, total cholesterol, LDL cholesterol and HDL cholesterol were determined with standard laboratory methods. Cholesterol parameters were only measured after 12 months $\mathrm{GH}$ treatment.

\section{Statistical analysis}

The clinical characteristics of the study population are presented as mean with ranges or S.E.M. The KolmogorovSmirnov test was used to test normality of variables (data were considered to be normally distributed when $P>0.05$ ). For data that did not meet the criteria for normality, logarithmic transformations were applied and are presented as geometric mean with ranges or $95 \%$ CI or if logarithmic transformation did not normalize data as median with interquartile range. A paired $t$-test or a Wilcoxon's signedrank test were used to test differences between baseline and 12 months of GH therapy. Age-adjusted Pearson's correlations were calculated between variables.

A $P$ value of 0.05 or less was considered statistically significant. Data were analyzed using SPSS 21 for Windows (SPSS, Inc.).

\section{Results}

\section{Baseline characteristics}

The left column of Table 1 shows the clinical baseline characteristics of the study population. At baseline, 38\% of all patients had total IGF1 levels $>-2$ s.D. despite a proven 
Table 1 Changes in clinical parameters during GH treatment.

\begin{tabular}{l} 
Characteristics study population \\
\hline Age (years) \\
Duration of GHD (years) \\
GHD-categories (no. of subjects) \\
AO-GHD \\
CO-GHD \\
GH-naïve \\
Previous GH treatment \\
Physical measurements \\
BMI (kg/m $\left.{ }^{2}\right)$ \\
Body fat (\%) \\
Waist (cm) \\
WHR (cm/cm) \\
Systolic BP (mmHg) \\
Diastolic BP (mmHg) \\
Laboratory testing \\
Fasting glucose level (mmol/l) \\
Insulin (pmol/l) \\
HOMA-B score \\
HOMA-IR score \\
Total IGF1 (nmol/l) \\
IGF1RSA (pmol/l) \\
IGF1RSA/total IGF1 (\%) \\
IGFBP1 ( $\mu$ g/l) \\
IGFBP3 (mg/l) \\
Total IGF1/IGFBP3 ratio \\
\end{tabular}

\begin{tabular}{c}
\hline $\begin{array}{c}\text { Baseline } \\
\text { (mean and range) }\end{array}$ \\
\hline $54.0^{\mathrm{A}}(18.0-79.4)$ \\
$9.5^{\mathrm{A}}(0-22)$ \\
84 \\
22 \\
22 \\
84
\end{tabular}

$28.4(17.9-49.8)$

32.5 (11.9-46.7)

99 (63-154)

$0.98(0.74-1.19)$

128 (96-163)

80 (58-102)

$4.7^{\mathrm{A}}(3.0-11.2)$

$36^{\mathrm{A}}(13-909)$

$82^{\mathrm{A}}(30-648)$

$0.7^{A}(0.3-9.3)$

$8.1(2.7-23.0)$

$115(20-337)$

$1.4(0.28-5.63)$

$23.0(0.4-131.2)$

$3.4(1.2-7.1)$

$0.07(0.03-0.18)$

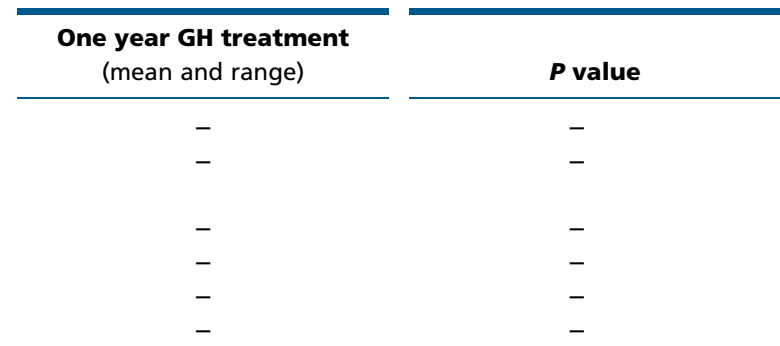

$28.3(17.5-50.3)$

$32.0(5.6-47.3)$

96 (70-150)

$0.96(0.76-1.11)$

134 (91-195)

82 (57-130)

0.32

$0.02^{\mathrm{a}}$

$<0.001^{\mathrm{a}}$

$0.002^{\mathrm{a}}$

$0.001^{\mathrm{a}}$

$0.04^{\mathrm{a}}$

$5.1^{\mathrm{A}}(3.9-9.7)$

$53^{\mathrm{A}}(12-324)$

$91^{A}(32-323)$

$1.0^{A}(0.3-6.8)$

14.9 (2.7-39.6)

183 (39-606)

$1.2(0.35-7.69)$

$17.2(0.4-124.6)$

$4.0(1.5-7.5)$

$0.11(0.03-0.31)$ $0.001^{a}$

$0.03^{\mathrm{a}}$

0.29

$0.008^{\mathrm{a}}$

$<0.001^{a}$

$<0.001^{\mathrm{a}}$

$0.003^{a}$

$<0.001^{\mathrm{a}}$

$<0.001^{\mathrm{a}}$

$<0.001^{\mathrm{a}}$

Changes in clinical parameters during GH treatment are shown as mean (or median ${ }^{A}$ ) and range. Body fat (as percentage of body mass); systolic BP, systolic blood pressure; diastolic BP, diastolic blood pressure; WHR, waist-to-hip ratio; HOMA-B, homeostasis model assessment of beta cell function; HOMA-IR, homeostasis model assessment of insulin resistance; IGF1RSA, circulating IGF1 receptor stimulating activity.

a Differences between baseline and 12 months of $\mathrm{GH}$ treatment statistically significant.

GHD by a decreased GH response in provocative test, while this was $22 \%$ for circulating IGF1RSA.

At baseline, total IGF1 was positively correlated to circulating IGF1RSA $(r=0.44, P<0.001)$ and IGFBP3 $(r=0.70, P<0.001)$ and inversely related to IGFBP1 $(r=-0.34, P \leq 0.001)$. Circulating IGF1RSA was positively related to IGFBP3 $(r=0.35, P<0.001)$ and inversely related to IGFBP1 $(r=-0.23, P=0.02)$. The IGF1/IGFBP3 ratio at baseline was 0.07 (0.03-0.18) (mean (range)). At baseline circulating IGF1RSA was positively related to the total IGF1/IGFBP3 ratio $(r=0.21, P=0.04)$.

\section{Changes in IGF1 parameters after 12 months of GH therapy}

The right column of Table 1 shows the changes in IGF1 parameters. Total IGF1 increased from $8.1 \mathrm{nmol} / 1$ (95\% CI 7.3-8.9) at baseline to $14.9 \mathrm{nmol} / \mathrm{l}(95 \% \mathrm{CI} 13.5-16.4)$ at 12 months $(P<0.001)(+83 \%)$. Circulating IGF1RSA increased from $115 \mathrm{pmol} / 1$ (95\% CI 103-127) to 183 pmol/1 (95\% CI 164-204) $(P<0.001)$ after 12 months $(+50 \%)$. The ratio of circulating IGF1RSA over total IGF1 decreased from 1.4 to $1.2 \%(P=0.003)$. IGFBP3 increased from $3.4 \mathrm{mg} / 1(95 \% \mathrm{CI} 3.1-3.5)$ at baseline to $4.0 \mathrm{mg} / 1$ (95\% CI 3.9-4.3) after 12 months $(P<0.001)$. IGFBP1 decreased from $23.0 \mu \mathrm{g} / 1$ (95\% CI 20.1-29.9) at baseline to $17.2 \mu \mathrm{g} / 1(95 \%$ CI $14.3-22.5)$ at 12 months $(P<0.001)$. The IGF1/IGFBP3 ratio increased from $0.07(0.03-0.18)$ to 0.11 (0.03-0.31) (mean (range)) during 12 months GH treatment $(+49 \%)$.

The mean $Z$-score of total IGF1 increased from $-2.24 \pm 1.04$ s.D. at baseline to $-0.60 \pm 1.45$ s.D. at 12 months $(P<0.001)$. The mean $Z$-score of circulating IGF1RSA increased from $-2.5 \pm 0.1$ to $-1.8 \pm 0.1$ s.D. after 12 months $(P<0.001)$ while the mean $Z$-score of IGFBP3 increased from $-1.6 \pm 0.1$ S.D. at baseline to $-0.6 \pm 0.1$ s.D. $(P<0.001)$. The percentage of patients with total IGF1 levels within the normal range increased from 38 to $81 \%$ (Fig. 1). For circulating IGF1RSA, this percentage increased from 22 to $51 \%$ (Fig. 1). Circulating IGF1RSA remained below normal in $43 \%$ of patients in whom total IGF1 had normalized.

At 12 months the mean $\mathrm{GH}$ dose was $0.20 \mathrm{mg} /$ day (range: 0.05-2.1). Patients in whom total IGF1 had 


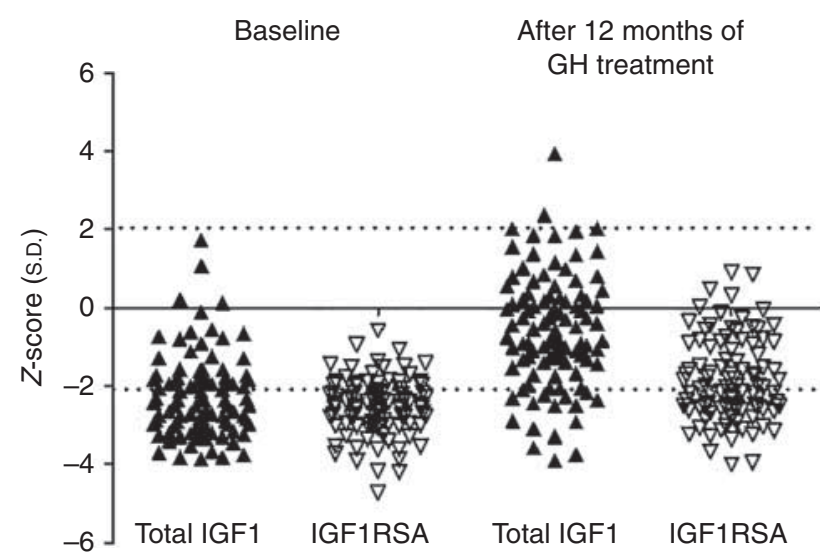

Figure 1

Z-scores of total IGF1 (black triangles) and circulating IGF1RSA (open triangles) at baseline (left) and after 12 months of GH therapy (right). Each triangle represents a patient.

The horizontal dotted lines represent the normal range in the healthy population (from -2 to +2 s.D.). At baseline $38 \%$ of all patients had total IGF1 levels $>-2$ s.D. compared to $22 \%$ for circulating IGF1RSA. After 12 months of GH treatment, this percentage increased to $81 \%$ for total IGF1, while for circulating IGF1RSA it increased to $51 \%$.

normalized used lower doses of GH compared to those in whom it had not normalized (0.19 compared to $0.28 \mathrm{mg} /$ day, $P=0.02$ ). These patients with a normal total IGF1 after 1 year also had higher IGFBP3 levels (4.2 mg/l vs $3.4 \mathrm{mg} / \mathrm{l}, P=0.001)$ and circulating IGF1RSA (202 pmol/1 vs $113 \mathrm{pmol} / \mathrm{l}, P \leq 0.001$ ). At 12 months the difference between these two groups in IGFBP1 levels just missed statistical significance $(15.5 \mu \mathrm{g} / \mathrm{l}$ vs $27.2 \mu \mathrm{g} / \mathrm{l}$, $P=0.07)$.

The mean GH dose between patients in whom circulating IGF1RSA had normalized compared to those in whom it remained subnormal did not differ $(0.22 \mathrm{mg} /$ day vs $0.19 \mathrm{mg} /$ day, $P=0.21)$. Patients in whom circulating IGF1RSA had normalized, had significantly higher total IGF1 levels (17.7 nmol/1 vs $12.6 \mathrm{nmol} / 1, \quad P<0.001)$ and higher IGFBP3 levels ( $4.3 \mathrm{mg} / 1$ vs $3.8 \mathrm{mg} / \mathrm{l}, P=0.04)$. In contrast, IGFBP1 levels were similar $(0.15 \mu \mathrm{g} / \mathrm{l}$ vs $0.17 \mu \mathrm{g} / \mathrm{l}, P=0.65)$ compared to those in whom circulating IGF1RSA had not normalized.

After 12 months GH treatment, total IGF1 was positively correlated to circulating IGF1RSA $(r=0.44$, $P \leq 0.001)$ and IGFBP3 $(r=0.50, P<0.001)$ and inversely correlated to IGFBP1 $(r=-0.20, P=0.05)$. There was no relationship between total IGF1 and GH dose $(r=0.13$, $P=0.20)$ and between circulating IGF1RSA and GH dose
( $r=0.11, P=0.30)$. At 12 months, circulating IGF1RSA was positively correlated to IGFBP3 $(r=0.23, P=0.03)$ and negatively correlated with IGFBP1 $(r=-0.22, P=0.04)$. After 12 months $\mathrm{GH}$ treatment circulating IGF1RSA was positively related to the total IGF1/IGFBP3 ratio $(r=0.37, P=0.001)$.

\section{Changes in clinical parameters after 12 months of GH therapy}

The right column of Table 1 shows the changes in clinical parameters. After 12 months of GH therapy, the percentage of fat mass, waist circumference and the WHR decreased significantly. In addition, after 12 months of GH treatment, systolic and diastolic blood pressure increased significantly. Also glucose and insulin levels as well as IR significantly increased, while beta function did not change.

Table 2 shows age-adjusted interrelationships between IGF1 parameters and several metabolic parameters after 12 months of GH treatment. Total IGF1 was inversely correlated to percentage of fat mass percentage $(r=-0.23$, $P=0.03$ ), but not to other parameters (Table 2). Circulating IGF1RSA was inversely correlated to glucose levels ( $r=-0.27, P=0.01$ ) but not to other parameters (Table 2 ). There were no differences in metabolic parameters between patients in who total IGF1 or circulating IGF1RSA had normalized compared to those in whom it had not.

\section{Discussion}

The most striking finding in our present study was that during 12 months of GH treatment, changes in circulating IGF1RSA did not parallel changes in total IGF1. Interestingly, IGF1RSA remained subnormal despite normalization of total IGF1 in a considerable proportion of patients. Moreover, the percentage increase of the IGF1/IGFBP3 ratio, which has been suggested to reflect an estimate of tissue available IGF1, was almost similar to the reported increase of IGF1RSA after GH treatment.

The question arises why changes in circulating IGF1RSA did not parallel changes in total IGF1.

Previously, we showed that 70-75\% of the variation of circulating IGF1RSA in a healthy population could not be explained by levels of total IGF1 (17). In the present study, about $78 \%$ of the variation of circulating IGF1RSA could not be explained by levels of total IGF1, demonstrating that circulating IGF1RSA was highly independent of total IGF1 in our study population. In addition, several studies have shown that the KIRA is more sensitive than total 


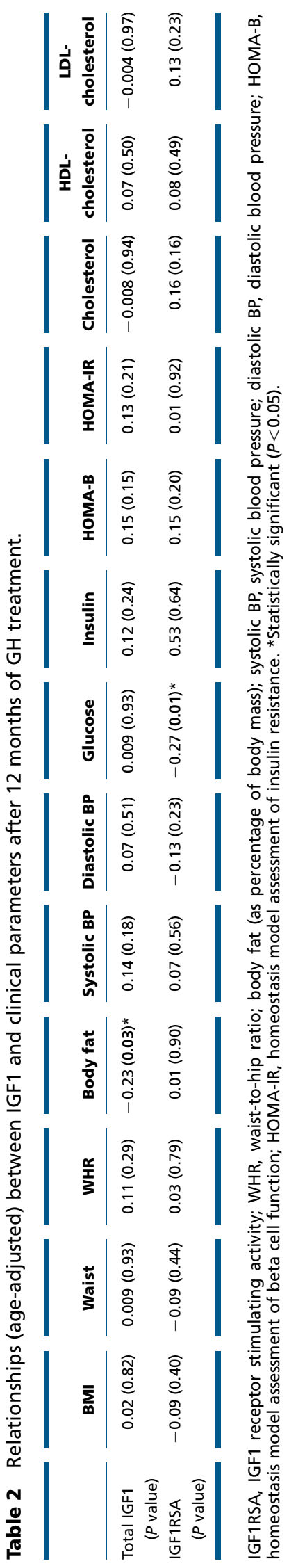

IGF1 immunoassays to detect differences in clinical states and to monitor changes of the IGF system during therapeutic interventions $(20,21,22,23,24)$. The IGF1 KIRA seems at least theoretically advantageous in biological relevance, since in contrast to the immunnoassays used to measure circulating total IGF1 levels, the IGF1 KIRA assay result is influenced by modifying effects of circulating IGFBPs and IGFBP proteases on the interactions between IGF1 and the IGF1R (13). In contrast, by extracting all IGFBPs prior to the measurement, total IGF1 immunoassays completely mask potentially modulating effects of IGFBPs on the interactions between IGF1 and the IGF1R. Thus, the IGF1 KIRA assay produces basically other information about the circulating IGF1 system than obtained by total IGF immunoassays.

Nevertheless, when measuring IGF1RSA by the KIRA assay one should keep in mind that outcomes are plotted against a universal background, namely an artificially IGF1R transfected cell system (25). With the KIRA it cannot be assessed whether activation of the (endogenous) IGF1R results in a balanced metabolic and mitogenic stimulating activity at cellular level in vivo. In addition, IGF1R activation at the local level in tissues is determined by a number of factors and not just by GH and/or circulating IGF1RSA (26). So one of the limitations of the KIRA is that it cannot provide information to what extent the ability of serum to activate IGF1Rs in vitro is indeed translated into biological responses of cells in vivo. In addition, an extra complicating factor in this respect may be that IGF1R and insulin receptors substantially may heterodimerize in vivo. Although in vitro these heterodimers act like an IGF1R, the exact physiologic role of heterodimers in vivo is presently unknown.

In untreated GHD, the amount of proteolyzed IGFBP3, the main circulating IGFBP, is not increased to maintain a reasonably high fraction of biologically active IGF1 $(12,27)$. Thus, in untreated GHD, the GH-IGF axis appears to be not able to compensate for the diminished IGF1 secretion. As a result of this, the amount of bioactive IGF1 remains significantly reduced $(12,27)$. In addition, in support of our findings, it has been reported that during treatment of GHD patients with GH, IGFBP3 proteolysis did not change significantly, suggesting that GH treatment has no major impact on IGFBP3 protease activity $(27,28)$.

In our study, the failure to normalize circulating IGF1RSA despite an increase in total IGF1 may be further related to the fact that $\mathrm{GH}$ doses were primarily titrated against circulating total IGF1 concentrations without taking into account changes in circulating IGF1RSA. 
Although normalization of the total IGF1 levels is considered to be the cornerstone for biochemical outcome of GH therapy in GHD, cross comparisons of the various commercially available total IGF1 assays show different performance characteristics especially when concentrations are measured during GH therapy (10). Anckaert et al. (10) demonstrated that long-term monitoring of GH therapy using serum total IGF1 values as outcome parameter lead to a different clinical interpretation and GH dose adjustments when different IGF1 immunoassays were used. Thus, it could be that the age-specific normative range values of the total IGF1 assay that was used in our study was inadequate and of poor quality. Moreover, Quarmby et al. (29) have suggested that assays calibrated against WHO IRR 87/518 report total IGF1 concentrations that are in excess of actual values, and that IGF1 concentration data based on assays calibrated against WHO IRR 87/518 (like the Immulite assay used in our study), are of questionable accuracy. Thus it could be that the effect of GH treatment on circulating total IGF1 concentrations in our study may have been (systematically) overestimated, accounting for another explanation for the observed discrepancy between total IGF1 and circulating IGF1RSA in our study. When this is indeed the case, it could be that there was a relative undertreatment of the GHD subjects with GH in our study.

On present evidence serum total IGF1 should be primarily regarded as a safety marker rather than a specific therapeutic marker (30). Our study did not clearly demonstrate that monitoring GHD subjects by measuring circulating IGF1RSA has greater physiological or clinical relevance than the traditional measurement of immunoreactive total IGF1. Total IGF1 levels were inversely related to the amount of body fat. Although we did not further study this, it is possible that the inverse relationship between IGF1 and fat mass is partly related to changes in IGFBP3 which has been shown to suppress fat cell differentiation (31). We further observed an inverse relationship between IGF1RSA and glucose levels, which fits with the well-known glucose lowering effects of IGF1 (32). Circulating IGF1RSA did not correlate with other relevant parameters of clinical outcome of GH therapy such as body composition and lipid profiles. However, one should realize that the GH dosing was not based on the results of circulating IGF1RSA but on circulating total IGF1 levels only. Furthermore, a limitation of our study was that 84 patients were not $\mathrm{GH}$ naïve but discontinued $\mathrm{GH}$ therapy for 4 weeks to obtain 'proxy' baseline values. This may have biased outcome and may have played a role in the lack of a relationship between body composition and lipids. On the other hand, the lack of a significant relationship between IGF1 and lipid profiles was not unexpected. Although GHD is associated with increased cholesterol levels which tend to normalize during GH replacement therapy, several observations indicate that direct actions of $\mathrm{GH}$ on the GH-receptor are more important for the regulation of plasma lipoprotein metabolism than IGF1 (25). Moreover, conflicting results on serum cholesterol during IGF1 treatment have been reported in patients with GH insensitivity syndrome (Laron dwarfism), including unchanged serum cholesterol $(26,30)$. Nevertheless, in order to answer the question whether circulating IGF1RSA could be a valuable tool to monitor GH therapy in GHD patients and whether titrating GH dose against circulating IGF1RSA results in a better (metabolic) clinical outcome than titrating against total IGF1 concentrations, prospective studies should be performed in which GH naïve subjects are randomized to GH dose titrated against circulating IGF1RSA vs GH dose titrated against total IGF1 concentrations. Such studies would be of great interest especially since we recently showed that circulating IGF1RSA in GHD patients is a better marker, compared to total IGF1, for some aspects of quality of life, indicating that circulating IGF1RSA better reflects IGF1-mediated actions than total IGF1 (14).

In conclusion, our study shows that there is discrepancy between the outcomes of the traditional measurement of total IGF1 and the IGF1R KIRA assay. During 12 months of GH treatment of GHD patients, changes in circulating IGF1RSA did not parallel changes in total IGF1. Despite normalization of total IGF1, circulating IGF1RSA remained subnormal in a considerable proportion of patients. Although at present our results have no immediate consequences for dosing GH therapy of GHD patients in clinical practice. Based on our findings, we propose future studies in GHD to examine whether titrating GH dose against circulating IGF1RSA results in a better clinical outcome than titrating against total IGF1.

\section{Declaration of interest}

The authors declare that there is no conflict of interest that could be perceived as prejudicing the impartiality of the research reported.

\section{Funding}

This work was supported by an unrestricted grant from Novo Nordisk A/S (Alphen aan de Rijn, The Netherlands). Novo Nordisk A/S had no involvement in the study design, in the collection, analysis and interpretation of data. 
Author contribution statement

A J Varewijck researched data and wrote the manuscript. S W J Lamberts reviewed/edited the manuscript and contributed to the discussion. A J van der Lely reviewed/edited the manuscript and contributed to the discussion. S J C M M Neggers researched data, reviewed/edited the manuscript and contributed to the discussion. L J Hofland reviewed/edited the manuscript and contributed to the discussion. J A M J L Janssen researched data, wrote the manuscript and reviewed/edited the manuscript.

\section{Acknowledgements}

The authors thank the patients for participation and the nursing staff of the Clinical Research Unit (B Poldermans, K Davidse and P Chotoo, all from the Erasmus MC, Rotterdam, The Netherlands) for their excellent patient care. In addition, they would like to thank P Uitterlinden (Erasmus MC, Rotterdam, The Netherlands) for performing the immunoassays for parameters of the IGF system.

\section{References}

1 Rosilio M, Blum WF, Edwards DJ, Shavrikova EP, Valle D, Lamberts SW, Erfurth EM, Webb SM, Ross RJ, Chihara Ket al. Long-term improvement of quality of life during growth hormone $(\mathrm{GH})$ replacement therapy in adults with GH deficiency, as measured by questions on life satisfaction-hypopituitarism (QLS-H). Journal of Clinical Endocrinology and Metabolism 200489 1684-1693. (doi:10.1210/jc.2003-030134)

2 Simpson H, Savine R, Sonksen P, Bengtsson BA, Carlsson L, Christiansen JS, Clemmons D, Cohen P, Hintz R, Ho K et al. Growth hormone replacement therapy for adults: into the new millennium. Growth Hormone \& IGF Research 200212 1-33. (doi:10.1054/ghir.2001. 0263)

3 Molitch ME, Clemmons DR, Malozowski S, Merriam GR \& Vance ML. Evaluation and treatment of adult growth hormone deficiency: an Endocrine Society clinical practice guideline. Journal of Clinical Endocrinology and Metabolism 201196 1587-1609. (doi:10.1210/jc. 2011-0179)

4 Svensson J, Johannsson G \& Bengtsson BA. Insulin-like growth factor-I in growth hormone-deficient adults: relationship to population-based normal values, body composition and insulin tolerance test. Clinical Endocrinology 199746 579-586. (doi:10.1046/j.1365-2265.1997. 1851001.x)

5 Ghigo E, Aimaretti G, Gianotti L, Bellone J, Arvat E \& Camanni F. New approach to the diagnosis of growth hormone deficiency in adults. European Journal of Endocrinology $1996 \mathbf{1 3 4} 352-356$. (doi:10.1530/eje.0. 1340352)

6 Varewijck AJ, Lamberts SW, Uitterlinden P, Hofland LJ \& Janssen JA. IGF-I bioactivity better reflects growth hormone deficiency than total IGF-I. Journal of Clinical Endocrinology and Metabolism 201196 2248-2254. (doi:10.1210/jc.2011-0051)

7 Consensus guidelines for the diagnosis and treatment of adults with growth hormone deficiency: summary statement of the Growth Hormone Research Society Workshop on Adult Growth Hormone Deficiency. Journal of Clinical Endocrinology and Metabolism $1998 \mathbf{8 3}$ 379-381.

8 Johannsson G, Grimby G, Sunnerhagen KS \& Bengtsson BA. Two years of growth hormone $(\mathrm{GH})$ treatment increase isometric and isokinetic muscle strength in GH-deficient adults. Journal of Clinical Endocrinology and Metabolism 199782 2877-2884.

9 Johannsson G, Sverrisdottir YB, Ellegard L, Lundberg PA \& Herlitz H. $\mathrm{GH}$ increases extracellular volume by stimulating sodium reabsorption in the distal nephron and preventing pressure natriuresis. Journal of
Clinical Endocrinology and Metabolism 200287 1743-1749. (doi:10.1210/ jcem.87.4.8394)

10 Anckaert E, Schiettecatte J, Vanbesien J, Smitz J, Velkeniers B \& De Schepper J. Variability among five different commercial IGF-1 immunoassays in conditions of childhood-onset GH deficiency and GH therapy. Acta Clinica Belgica 200661 335-339. (doi:10.1179/acb. 2006.053)

11 Clemmons DR. Commercial assays available for insulin-like growth factor I and their use in diagnosing growth hormone deficiency. Hormone Research 200155 (Suppl 2) 73-79. (doi:10.1159/000063480)

12 Clemmons DR. IGF-I assays: current assay methodologies and their limitations. Pituitary 200710 121-128. (doi:10.1007/s11102-0070032-z)

13 Chen JW, Ledet T, Orskov H, Jessen N, Lund S, Whittaker J, De Meyts P, Larsen MB, Christiansen JS \& Frystyk J. A highly sensitive and specific assay for determination of IGF-I bioactivity in human serum. American Journal of Physiology. Endocrinology and Metabolism 2003284 E1149-E1155. (doi:10.1152/ajpendo.00410.2002)

14 Varewijck AJ, Lamberts SW, Neggers SJ, Hofland LJ \& Janssen JA. IGF-I bioactivity might reflect different aspects of quality of life than total IGF-I in GH-deficient patients during GH treatment. Journal of Clinical Endocrinology and Metabolism 201398 761-768. (doi:10.1210/jc. 2012-2901)

15 Cook DM, Yuen KC, Biller BM, Kemp SF \& Vance ML. American Association of Clinical Endocrinologists medical guidelines for clinical practice for growth hormone use in growth hormone-deficient adults and transition patients - 2009 update. Endocrine Practice 200915 (Suppl 2) 1-29. (doi:10.4158/EP.15.S2.1)

16 Levy JC, Matthews DR \& Hermans MP. Correct homeostasis model assessment (HOMA) evaluation uses the computer program. Diabetes Care 199821 2191-2192. (doi:10.2337/diacare.21.12.2191)

17 Brugts MP, Ranke MB, Hofland LJ, van der Wansem K, Weber K, Frystyk J, Lamberts SW \& Janssen JA. Normal values of circulating insulin-like growth factor-I bioactivity in the healthy population: comparison with five widely used IGF-I immunoassays. Journal of Clinical Endocrinology and Metabolism 200893 2539-2545. (doi:10.1210/ jc.2007-2454)

18 Elmlinger MW, Kuhnel W, Weber MM \& Ranke MB. Reference ranges for two automated chemiluminescent assays for serum insulin-like growth factor I (IGF-I) and IGF-binding protein 3 (IGFBP-3). Clinical Chemistry and Laboratory Medicine 200442 654-664. (doi:10.1515/ CCLM.2004.112)

19 Juul A, Main K, Blum WF, Lindholm J, Ranke MB \& Skakkebaek NE. The ratio between serum levels of insulin-like growth factor (IGF)-I and the IGF binding proteins (IGFBP-1, 2 and 3) decreases with age in healthy adults and is increased in acromegalic patients. Clinical Endocrinology 199441 85-93. (doi:10.1111/j.1365-2265.1994.tb03788.x)

20 Brugts MP, Tjiong HL, Rietveld T, Wattimena JL, van den Berg JW, Fieren MW \& Janssen JA. Bioactive rather than total IGF-I is involved in acute responses to nutritional interventions in CAPD patients. Nephrology, Dialysis, Transplantation 201025 940-946. (doi:10.1093/ ndt/gfp576)

21 Brugts MP, van den Beld AW, Hofland LJ, van der Wansem K, van Koetsveld PM, Frystyk J, Lamberts SW \& Janssen JA. Low circulating insulin-like growth factor I bioactivity in elderly men is associated with increased mortality. Journal of Clinical Endocrinology and Metabolism 200893 2515-2522. (doi:10.1210/jc.2007-1633)

22 Gielen M, Mesotten D, Brugts M, Coopmans W, Van Herck E, Vanhorebeek I, Baxter R, Lamberts S, Janssen JA \& Van den Berghe G. Effect of intensive insulin therapy on the somatotropic axis of critically ill children. Journal of Clinical Endocrinology and Metabolism 201196 2558-2566. (doi:10.1210/jc.2010-3045)

23 Moller L, Dalman L, Norrelund H, Billestrup N, Frystyk J, Moller N \& Jorgensen JO. Impact of fasting on growth hormone signaling and action in muscle and fat. Journal of Clinical Endocrinology and Metabolism 200994 965-972. (doi:10.1210/jc.2008-1385) 
24 Beardsall K, Ogilvy-Stuart AL, Frystyk J, Chen JW, Thompson M, Ahluwalia J, Ong KK \& Dunger DB. Early elective insulin therapy can reduce hyperglycemia and increase insulin-like growth factor-I levels in very low birth weight infants. Journal of Pediatrics 2007151 611-617. 617 e611. (doi:10.1016/j.jpeds.2007.04.068)

25 Brugts M. IGF-I bioactivity in aging, health and disease. Erasmus University Rotterdam, 2010. Retrieved from http://hdl.handle.net/1765/17722

26 Janssen JA. Advantages and disadvantages of GH/IGF-I combination treatment. Reviews in Endocrine \& Metabolic Disorders 200910 157-162. (doi:10.1007/s11154-008-9081-5)

27 Lassarre C, Duron F \& Binoux M. Use of the ligand immunofunctional assay for human insulin-like growth factor ((IGF) binding protein-3 (IGFBP-3) to analyze IGFBP-3 proteolysis and igf-i bioavailability in healthy adults, GH-deficient and acromegalic patients, and diabetics. Journal of Clinical Endocrinology and Metabolism 200186 1942-1952. (doi:10.1210/jcem.86.5.7467)

28 Skjaerbaek C, Kaal A, Moller J, Vahl N, Weeke J, Orskov H \& Flyvbjerg A. No effect of growth hormone on serum insulin-like growth factor binding protein-3 proteolysis. Journal of Clinical Endocrinology and Metabolism 199883 1206-1210. (doi:10.1210/jcem. 83.4.4686)

29 Quarmby V, Quan C, Ling V, Compton P \& Canova-Davis E. How much insulin-like growth factor I (IGF-I) circulates? Impact of standardization on IGF-I assay accuracy Journal of Clinical Endocrinology and Metabolism 199883 1211-1216. (doi:10.1210/jcem. 83.4.4727)

30 Monson JP. Monitoring of insulin-like growth factors during growth hormone treatment: adulthood growth hormone deficiency. Endocrine Development 20059 89-99. (doi:10.1159/000085759)

31 Kim HS. Role of insulin-like growth factor binding protein-3 in glucose and lipid metabolism. Annals of Pediatric Endocrinology \& Metabolism 201318 9-12. (doi:10.6065/apem.2013.18.1.9)

32 Clemmons DR. Metabolic actions of insulin-like growth factor-I in normal physiology and diabetes. Endocrinology and Metabolism Clinics of North America 201241 425-443, vii-viii. (doi:10.1016/j.ecl. 2012.04.017)

Received 13 January 2015

Revised version received 29 April 2015

Accepted 5 May 2015 